\title{
0826 THE HUNGARIAN ALLIANCE AGAINST DEPRESSION: STRENGTHENING SOCIAL CAPITAL IN THE INTERVENTION REGION
}

M Kopp*, A Szekely, M Bagi Correspondence: National Suicide Research Foundation, 1 Perrott Avenue, College Rd., Cork, n/a, Ireland

\subsection{6/ip.2010.029215.826}

The European Alliance Against Depression (EAAD) was formed in 2004 with funding from the European Commission to create community-based networks to employ an evidencebased approach to improving the care of depressed persons and preventing suicidality. The first intervention region of the Hungarian EAAD programme was Szolnok and its sub-region. Compared to the average of the previous 9 years in 2005, in the first year of the programme suicide rates decreased with $57 \%$, in 2006 with $47 \%$ in Szolnok city. This means that the suicide rate was $30.1 / 100.000$ in $2004,13.1 / 100.000$ in 2005 and $14.5 / 100.000$ in 2006. The decrease was higher among men than among women. Most important elements of the programme: destigmatisation of depression and suicidal ideations, more help seeking, first of all among men, increasing number of calls at the hot-line services (50\% male calls), increasing patient visits at the hospitals psychiatry department. Strengthening local networks based on local needs and facilities, strengthening the collaboration among the local helping professionals, that is a multi-focal and social capital building approach seems to be the most important aspect of the programme. 